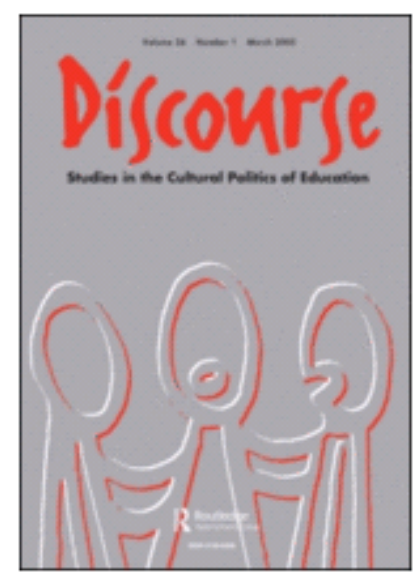

\title{
Engaging with policy actors and the discursive politics of school-related gender-based violence in Ethiopia and Zambia.
}

\begin{tabular}{|r|l|}
\hline Journal: & Discourse: Studies in the Cultural Politics of Education \\
\hline Manuscript ID & CDIS-2019-0104.R1 \\
\hline Manuscript Type: & Original Article \\
\hline Keywords: & $\begin{array}{l}\text { SRGBV, policy enactment, the discursive politics of gender equality, } \\
\text { Ethiopia, Zambia, gender, violence }\end{array}$ \\
\hline \multicolumn{2}{|l}{} \\
\hline
\end{tabular}

\section{SCHOLARONE ${ }^{m}$ Manuscripts}




\title{
Engaging with policy actors and the discursive politics of school-related gender-based violence in Ethiopia and Zambia.
}

\begin{abstract}
School-related gender-based violence (SRGBV) has received growing attention in policy and practice over the past decade, increasingly attended to in national and international contexts. Yet there remains a need to understand more fully the processes and actors, through which this policy enactment takes place. Drawing on theoretical work on policy discourse in education (Ball et al, 2011) and gender (Lombardo et al, 2009) this article analyses understandings of SRGBV by policy stakeholders in Ethiopia and Zambia. The analysis shows how the concept is discursively stretched by actors in positive ways, as well as shrunk and fixed in ways that limit its application, in gendered and political processes. We also extend Lombardo et al's conceptual framework to propose a new dimension of making 'bold' that involves contextualising and revealing less visible dimensions of SRGBV. We propose SRGBV offers a point where contestation between policy actors and sectors, and between contrasting understandings of violence, gender and socio-cultural norms, is inevitable. Opportunities for dialogue that include recognition of the everyday and gendered manifestations of violence may offer a contribution to facilitating policy enactment that moves towards a holistic and inclusive account of SRGBV, with the potential to have positive material impacts on equality.
\end{abstract}

Keywords; SRGBV, gender, violence, policy enactment, the discursive politics of gender equality, Ethiopia, Zambia.

\section{Introduction}


Recognition has grown on the global stage that violence against children is widespread and commonplace (Ravi \& Ahluwalia, 2017). School-related gender-based violence (SRGBV) has received increasing attention in research, policy and practice over the past decade, nationally and internationally. Research has illustrated the multi-dimensionality of violence, with acts of physical, sexual and emotional force embedded within everyday interactions, and rooted in the structural violence of inequitable socio-economic and political structures and institutions (Parkes, 2015). Multi-dimensional framings are also increasingly deployed by multi-lateral and bi-lateral organisations (UNESCO, 2016; UNGEI, 2018; USAID, 2016), and there has been growing consensus in the discursive framing of SRGBV, reflected in publicised definitions by different organisations, and as seen in the $2015 \mathrm{UN}$ resolution on SRGBV to which 58 countries are signatories. This defines SRGBV as:

(a) is an expression of gender stereotyping and gender inequality at work in all of our societies, the reproduction of which is sustained through that violence;

(b) includes all forms of violence and threats of violence directed specifically against a pupil because of gender and/or that affects girls and boys disproportionately, as the case may be;

(c) can be of a physical, sexual or psychological nature and take the form of intimidation, punishment, ostracism, corporal punishment, bullying, humiliation and degrading treatments, harassment, sexual abuses and exploitation;

(d) can be inflicted by pupils, teachers or members of the educational community;

(e) can occur: within the school; in its outbuildings; on the way to or from school; during extracurricular activities or through the increasingly widespread use of information and communication technology (ICT) (cyberbullying, sexual harassment through mobile phones); 
(f) can have serious and long-term consequences such as: loss of confidence and self-esteem, impaired physical and psychological health, early and unintended pregnancies, depressions, reduced learning achievement, absenteeism and drop-out, aggressive behaviours etc.

$(196 / \mathrm{EX} / 30,2015)$

There has been considerable work building towards this consensus, that frames SRGBV as a broad array of physical, sexual and psychological acts, underpinned by gender, and that can be experienced and perpetrated by an array of actors, in multiple locations. This paper considers to what extent this consensus is reflected by governments and other organisations responsible for taking forward actions to address SRGBV in two African countries.

However, remarkably few studies have attended to SRGBV policy processes (Parkes, Heslop, Johnson Ross, Westerveld \& Unterhalter, 2016). This article draws on new data from Ethiopia and Zambia to examine the ways in which SRGBV is conceptualized by government officials, service providers, and NGO programme staff, and to consider the implications for violence prevention. Drawing on the theoretical notions of 'policy enactment' (Ball, Maguire \& Braun, 2011) and the 'discursive politics of gender equality' (Lombardo, Meier \& Verloo, 2009) we consider: the types of violence policy actors focus upon; how gender and sexuality feature within this; and how less visible dimensions of the concept come in to play in particular contexts in the process of policy enactment.

\section{Existing literature \& theoretical framework}

The evolution of SRGBV as conceptually multi-dimensional within the academic, policy and practice literature has taken place over time - moving to encompass the relational and institutional dimensions of violence, along with consideration of acts themselves (Parkes et al, 2013). African scholars have generated a rich body of evidence documenting the 
$\underline{\text { commonplace nature of multiple forms of SRGBV, including at primary (Chikwiri \& }}$

Lemmer, 2014) and secondary (Muhangi, 2017) levels, in a range of country contexts

including Ethiopia and Zambia. For example, Mulugeta (2016) and Pankhurst, Negussi and

Mulugeta (2016) review existing and analyse new qualitative and quantitative data in relation

to young people's experiences of violence in Ethiopia. Studies have also examined ways of

addressing this (Kyegombe et al, 2017; Mayeza \& Bhana, 2017), including in Zambia

considering the role of teacher training in psychosocial care and support (Kaljee et al, 2017).

Reviews have acknowledged the expansion of national legislative and policy frameworks relating to gender-based violence and SRGBV, but criticised lack of political will, lack of cross-sectoral support, and a tendency to create national policies without action plans or budgetary allocation (Leach, Dunne \& Salvi, 2014; Ellsberg et al, 2015). A small number of

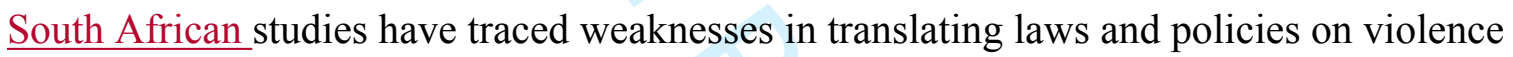
against children from national to local levels, for example with competing policies and directives hindering attempts at inter-sectoral approaches to prevention (Matzopoulos \& Myers, 2014; Centre for Applied Legal Studies, 2014). Parkes (2016) traces the growth in SRGBV policy from 2000 - but in a study of South Africa, Brazil and Liberia points to the disconnect between conceptualisation and intention, and local action on violence. Large-scale reviews have also highlighted a lack of evidence informed policy on SRGBV (Parkes et al, 2016; Leach et al, 2014), and there remain gaps in understanding of the relationship between policy and evidence, and policy and its enactment. This article contributes to addressing this gap by focusing on the discursive understanding of SRGBV by policy actors in Ethiopia and Zambia.

Some earlier scholarship has considered gender and education policy more widely in developing contexts, highlighting the misalignment between policy and practice. As early as 1997, Stromquist highlighted the global failure to implement gender sensitive educational 
strategies (in contrast to policy) (Stromquist, 1997). In Malawi, Tanzania and Zimbabwe, Swainson (2000) considered factors shaping the design and implementation of gender policies in education. This revealed the significance of the interface and interaction (including tension) between policy and programming, and national and international actors. In Ethiopia, research on comprehensive sex education has shown how certain dimensions of work on gender (including the perspectives of young people, and its relational dimensions) can be squeezed out in practice (Le Mat, 2017; Le Mat, Kosar-Altinyelken, Bos \& Volman, 2019).

This article also builds on studies from the global South that have explored the way actors, including NGO workers, negotiate, interpret and enact conceptions of gender justice in education. This has included recognition of the ambivalent and complex nature of dialogic processes between different local and national stakeholders (Sharma, Verma \& Arur, 2013). Studies have also highlighted the interactions and disconnections between distinct international, national and local understandings of gender and gender-based violence (Abramowitz \& Moran, 2012) - stressing the need for serious engagement with local specificities if manifestations and underlying causes of violence are to be improved. Research has also revealed how norms, professional cultures, institutional arrangements and gendered identities influence how gender policies are implemented among district level education officials (Unterhalter et al, 2012), NGO staff (DeJaeghere \& Wiger, 2013) and teacher training institutions (Unterhalter \& North, 2017).

Another grouping of work has considered the process of policy enactment and the actors involved (Ball, Maguire, Braun \& Hoskins, 2011a, 2011b), however this has focused on the school-level in the global North. Thus Maguire at al (2015) highlight the messiness of policy enactment, including unintended as well as intended consequences. They emphasise the significance of individual actors in this process, as do Perryman et al (2017). Viczko and 
Riveros too have highlighted the growing interest in the interpretation and translation inherent in moving from policy to practice (Viczko \& Riveros, 2015). Building on this scholarship in different contexts we bring this attention to discursive processes of enactment to developing contexts, with a careful examination of the understanding and use of SRGBV by national policy stakeholders in Ethiopia and Zambia.

Our analysis employs a theoretical framework that draws on Lombardo, Meier and Verloo's notion of the 'discursive politics of gender equality' (2009), and Ball, Maguire, and Braun's notion of 'policy enactment' (2011). Lombardo et al's work stems from feminist approaches to politics and policy analysis drawing on Foucauldian understandings of discourse to examine the changing way the concept of gender equality has been operationalised in a range of European and US policy contexts. They propose this takes place through four processes, conceptualising these as: fixing - a temporary fixing of its meaning following struggle; shrinking - when the concept is pinned down to specific and narrowed content; stretching when it is expanded to enable the inclusion of a wider range of concerns or topics; bending when its meaning is shaped to the benefit of a different agenda or aim. Their approach enables recognition of the difference between the labelling, content and 'strategy' of gender equality policies. They consider both the intended and unintended consequences of policy frames, and the critical role of actors in constructing this discursive space - arguing that studying the way gender equality is framed by people interacting within different political contexts and debates requires a discursive approach.

Although examining a different concept and context - their work usefully unpicks the political nature of the discursive processes at play in relation to actors and policy on gender, the mobile nature of this through time and across different contexts, and its implications, which we draw on here in our consideration of the concept of SRGBV. With a similarly Foucauldian lineage, Ball as early as 1990 was displaying the utility of taking a discursive 
approach to thinking about education and education policy (although not concerned specifically with gender). The notion of 'policy enactment' serves to expand from policy implementation to consider the messy dynamism inherent in this process, as well as the significance of different contexts and actors at the level of UK schools. We use this to look at the understandings of national level policy stakeholders engaged with the formation, interpretation and enactment of policy linked to SRGBV.

\section{Methods}

This article is based on the analysis of qualitative data drawn from workshops, interviews and focus groups carried out as part of a collaborative action research initiative with the governments of Ethiopia and Zambia and UNICEF (the work also took place in Togo and Cote d'Ivoire, discussed elsewhere). The research's overall aim was to strengthen the production and use of evidence in SRGBV policy and practice, and the initiative took place over three years, 2015-2017. The research was structured in two phases. We understand action research broadly as practice focused research, carried out with practitioners, and aimed at a specific problem or change context. This involves research developed through a staged reflective process of problem solving among a team to achieve a longer term goal (McNiff \& Whitehead, 2011). In the first phase a global literature review was conducted [Authors], followed by scoping studies in each country to review the evidence, policy and practice on SRGBV. Findings from these studies informed the second phase, in which country teams developed and implemented action plans on SRGBV. The data discussed in this paper is drawn from the scoping studies.

Data for the scoping studies consisted of a series of interactive workshops, and semistructured stakeholder interviews (23 in Ethiopia and 26 in Zambia). Two workshops, hosted 
by Education Ministries and UNICEF, were held in each country - the first to gather and discuss information and insights from participants, the second to present draft findings for discussion and feedback. In the first workshops (lasting two days each), participants discussed existing global and national research evidence, policy and practice on SRGBV, and in smaller groups undertook a series of reflective exercises that sought to map and discuss the dimensions of law and policy, programming and practice, and data and evidence. Workshop participants were selected to represent a spread of types and sectors of actors engaged with SRGBV, based on discussions between the UNICEF country offices, education ministry officials, and the research leads. Follow up interviews were held with a sample representing a range of state and non-state actors in the education, gender, justice and health sectors, predominantly at national level but with some at regional and district level. Interviewees included, for example, civil servants with responsibility for gender or violence against children, representatives from NGOs working on questions of youth/gender/violence/education, and representatives from teachers' organisations. These interviews took place at locations convenient to interviewees - usually in private rooms at their places of work. National researchers were recruited to work on the project, and findings and reports were consulted upon and validated with in-country partners.

Ethical approval was gained through the [Authors' institution] Ethics Committee. All participants were provided with written and verbal information and invited to opt in to the research. Transcribed data was coded using NVivo, with codes developed based on the research questions and initial examination of the data by the research team. The analysis for this paper focuses particularly on data relating to stakeholders' understandings of SRGBV and its causes. 


\section{Findings}

\section{Shrinking and fixing SRGBV - extreme versus everyday violence}

As discussed in the introduction, there has been growing consensus among global policy networks, that frames SRGBV as a broad array of physical, sexual and psychological acts, underpinned by gender, and that can be experienced and perpetrated by an array of actors, in multiple locations. In Lombardo et al's terminology (2009) this is a fixing of the concept at this level of international policy. Yet, given the temporary and political nature of such 'fixing', the messiness of policy enactment, and the multi-faceted nature of the concept there remains significant opportunity for varying emphases and interpretation. Asked about their understandings of SRGBV, many of the Ethiopian and Zambian policy actors articulated these facets of physical, sexual and psychological violence, in different contexts in and around schools, and experienced and perpetrated by multiple actors. For example, one interviewee in Ethiopia reported:

For instance, girls are harassed while going to and coming from schools. By and large harassment, both physical and verbal, and sexual violence are the common forms of SRGBV. Children are battered at home and school. Boys and girls are bullied by children on the way to or from schools and in schools. There is also sexual exploitation and rape. (NGO worker) (Ethiopia).

This illustrates a fairly succinct summary from an NGO worker - including different types, locations, victims and perpetrators, which was also reflected in our data from Zambian stakeholders, for example:

SRGBV is violence that takes place - may be from a teacher is done by a teacher on a pupil; may be physically, emotionally or psychologically. Or maybe by a pupil to a 
teacher or may be a pupil to a pupil; or may be a teacher to a teacher. (Education Union worker) (Zambia).

However, although many policy actors broadly echoed the framing of SRGBV articulated in the UN resolution, there were also variations in its discursive presentation - across actors in both countries, and between different professional roles of actors. For example, actors in both countries emphasised particular types and experiences of violence, with the effect of fixing and shrinking the concept. Often they focused on the most serious occurrences of violence and abuse, particularly sexual resulting in pregnancy, depicting these acts as perpetrated by adults against children, and usually located away from the school itself. For example, in interviews with both NGO and state actors in Ethiopia and Zambia:

Though the degree varies, schoolgirls are sexually harassed and raped by family members, students, teachers, and locals on the way to school, in school and surrounding areas in almost all regions. Rape is one of the reasons for high dropout rates of girls from school. The problem is higher in rural parts of the country than urban settings. Culturally, in rural areas, most parents don't discuss things with their children. When cases of rape are reported by girls and get the attention of parents, as a settlement girls are forced to marry perpetrators; especially when perpetrators, like teachers, are believed to have a livelihood to lead a family. The trend is better in urban settings. Boys and girls are relatively higher in confidence and aware of their rights. (NGO worker) (Ethiopia)

Over this weekend I was reading in the Post Newspaper a teacher, I think in a way violated a girl pupil at boarding school. He invited this girl child to his home and while the girl was in he locked the door inside and was attempting to rape her - and those are some of the issues that we have been trying to deal with through our 
gender sub-committee because these issues really are rampant. (NGO worker) (Zambia)

In the context of group discussions this emphasis on extreme forms of violence often dominated, being voiced by actors working in legal professions, reflecting the seriousness of the offences they encounter, but but also by those in a range of government and NGO roles. Accounts drew on hear-say and dramatic media coverage, as opposed to direct experience, research evidence or data to support claims. This focus can serve to shrink SRGBV, neglecting more mundane, 'everyday' violence, such as psychological bullying or corporal punishment, despite evidence of their prevalence (Heslop, Parkes, Johnson Ross, Alito \& Turner, 2019; Pankhurst, Negussie \& Mulugeta, 2016; SAQMEC, 2007), and in the case of corporal punishment its illegality. Girls are depicted as 'uncomplicated' female victims lacking in context or agency. There is a shrinking from the interconnected and multi-faceted nature of SRGBV, and from the underlying structures of inequality that are connected both to 'everyday' and 'extreme' manifestations.

There were, however, some exceptions to the general trend to emphasise extreme violence. In some cases, often prompted by the researchers, actors more involved with teaching or programmatic interventions with young people did refer to bullying and corporal punishment. For example, this NGO worker explained:

The bullying that is more common is the senior graders bullying the first or second graders. Bullying that has been reported includes the senior graders wanting to grab the food from the juniors, they make them do extra work, the portion that is supposed to be cleaned by the Grade 12 for example, the Grade 12 will go and bully the junior graders to say you have to do this home work for me or you have to wash my clothes. (NGO worker) (Zambia). 
However, in both countries the occurrence of corporal punishment was usually minimised when raised, as illustrated by this education official:

IN: And what sort do you think is the most common [form of SRGBV]?

AB: The most common is sexual harassment and sexual abuse.

$\mathrm{IN}$ : What about bullying or corporal punishment?

AB: Corporal punishment is almost eradicated due to the policies, it's a crime. I think it has been minimized compared to the past. (Education union worker) (Zambia).

In this example, there is arguably a particular connection between the interests a teacher representative might have in deflecting this suggestion, although other officials also reflected this perspective. In contrast, an unusual account of widespread corporal punishment was provided by a worker at a national NGO supporting young people in Zambia who explained:

It's everywhere. Schools. Homes. We went to $[\mathrm{X}]$ primary school - they were making a noise and you know what the headmistress said? The only language an African child understands is a whip and a pinch. That in itself is clear indication that corporal punishment is still going on, though it has been abolished. (NGO worker) (Zambia)

This stakeholder with close experience supporting young people who have reported violence, clearly articulates the continued normalisation of corporal punishment. That this should not be raised by other policy actors reflects the politics surrounding the practice, particularly as in both countries corporal punishment has been illegal for a significant period. The (non)recognition that this legal change has not been effective in practice is both an illustration of its weak enactment, and of the discursive shrinking of SRGBV. For 
government workers, such as education ministry officials (at national or local levels), teachers, and union representatives, who may see themselves as directly responsible for enacting the legislation, the continuing practice may be perceived as illustrative of failure. It may be in their interests to under-state the extent of such forms of violence. These examples illustrate how the professional positioning of policy actors influences the ways in which they shrink and fix meanings around SRGBV.

\section{Stretching SRGBV around gender and sexuality}

Conceptualisations of SRGBV were also shaped by policy actors' understandings of gender and gender-based violence. In some cases, awareness of the power dynamics inherent in gender relations enabled them to stretch SRGBV to include violence of different sorts experienced by men and boys. For example:

they are gendered in that they may be targeted at a female or the other way round. Or the female at a man. They are perpetuated using a gender disposition based on the power play that could be there. For example, if I want to mistreat someone based on their gender, it is called gender-based violence. I could do that through remarking negatively about them, I could do that through demeaning them. I could do that through speaking very lowly on them, as opposed to what should have been the real issue. So gender-based violence could be physical in that regard, it could be psychological; at the most gender-based violence could be sexual. (NGO worker) (Zambia)

However, perspectives like these, that conceive of gender as relational, and of gender relations as generative of violence affecting men and boys, as well as girls and women, were relatively unusual, and put forward predominantly by NGO workers in established organisations with presence in more than one country (whether based in the global North or 
South). This quotation also illustrates a frequent slippage between gender-based violence (GBV) and SRGBV when being asked specifically about the latter. This could contribute to the emphasis placed on sexual violence discussed earlier, given the legacy of women's rights organisations working on physical and sexual forms of GBV with adult women (Kelly, 2005; Peters \& Wolper, 1995). Yet it is also potentially a result of the process through which SRGBV has become a conceptual policy node in its own right over the past decade, drawing together and building on work that has taken place on both GBV and children's rights (for example, see Leach et al, 2014). Such stretching broadens the framing of SRGBV, with the potential to incorporate multiple forms of inequality.

On the other hand, gendered ideas about biology and sexuality could also be seen at times to stretch SRGBV in discriminatory ways - for example leading to homosexual relations of any type being considered a form of SRGBV:

This does not mean that boys are free from this kind of problem. These days boys in city administrations and towns are also facing many challenges like addiction to drugs, cigarette, khat and alcohol, pornography, lesbian practice, for instance there are number of cases reported that young boys are raped by other adult men and the likes, which is obviously affecting their personal as well as educational life. I think we can see those challenges and problems as gender-based violence too. (Government worker) (Ethiopia)

Such perspectives, where homosexuality is viewed as a form of SRGBV (whether consensual sex, or rape or assault by a homosexual person), was fairly widespread among the policy actors, though some also spoke out against such views. Also commonplace were gendered tropes that the biological needs of men, and the tempting nature of women, led to violence, as this interviewee reflected when discussing who seeks support following abuse: 
Even if someone is beaten they are not free to come, maybe they will laugh at him saying a man being beaten by a woman. Then what I have also observed is that women starve their husbands sexually. So some men are forced to go for a daughter or an orphan in the home. They have sexual intercourse with someone he is not supposed to. Then when you bring them maybe ... maybe defilement or what; they don't explain those details, but some say that's what happens when a woman says "I don't want" maybe two, three months, you know men are not like us women. When my husband dies, maybe I can live for the rest of my life, I will just concentrate on my children or the farm, but with men it's something different. Sometimes the women also contribute. (Government support worker) (Zambia)

Homophobic attitudes, and beliefs that responsibility for women and girl's harassment is tied to their own behaviour or dress reflect certain conservative social (and particularly religious) views on gender and sexuality held by some people in both Ethiopia and Zambia (for example, as reflected in data from the most recent DHS 2014 in Zambia, and 2011 in Ethiopia). That such views are being articulated by people who are directly responsible for developing and enacting SRGBV policy at national and local levels, and across different sectors (including education and health) is particularly concerning. Attempts to enact policy or programmatic interventions in this area which do not engage with these points of contestation, such as discourses around gender and sexuality, will run the risk of enacting only partial elements of a holistic strategy on SRGBV, or have the potential to reproduce structures that reinforce inequality and discrimination. Ensuring the involvement of policy actors with an in-depth understanding of gender in such processes are important. Without this, it is evident that however nuanced or well-framed an SRGBV policy might be, this does not guarantee it will be enacted in this spirit.

\section{Bending or making bold}


Our analysis also revealed ways in which the concept of SRGBV was being shaped to expand or emphasise elements in relation to specific concerns or manifestations of SRGBV in each country. In contrast to Lombardo's notion of 'bending' where concepts are misused to attend to a different issue, our analysis adds a further dimension of making 'bold' particular dimensions related to the concept. So, for example, in Zambia actors spoke about risks faced by young people living in private rented accommodation away from home to attend secondary school - bringing into view themes outside the scope of the UN definition of SRGBV (which refers only to the school premises or journey to school). Another dimension made bold in the Zambian context was the significance of initiation practices, undergone by both girls and boys:

GE: they are ceremonies where, when a girl becomes of age they take them in exclusion and they are taught things concerning marriage - like you are now a big girl you should behave like this; a boy to a man so on and so forth. All these things impact negatively on a girl because after the initiation ceremony they go out there back to class they see a man as somebody they should respect... It is good for them if they shouldn't speak out... and they are taught how to handle a man.

IN: How to handle a man?

GE: How to have sex with a man and what to do, so that they would want to experiment... because their mind is already out there and they are already taught and they will end up going to sleep with a man or a fellow pupil and experiment what they were taught... So for me I would say initiation ceremonies for the girls is not very good when they are still very young. (Education union worker) (Zambia)

This interviewee reflected on how a particular discourse of female sexuality encouraged at a young age, focused on subservience and male pleasure, could contribute to unequal and unwanted sexual relations or abuse. This is also situated in a wider context of inequality 
between men and women, inequitable behavioural standards, and lack of alternative information or advice in relation to healthy sex and relationships. By making bold issues like school distance and sexual initiation practices, these actors are taking steps to bring them onto the policy agenda. Significantly, attempts to introduce comprehensive sexuality education (CSE) are ongoing in both countries, although are controversial. Given the rising attention paid to SRGBV it could be that linking discussions on CSE with those on SRGBV may create opportunities for driving forward such work.

In Ethiopia concerns were made bold about practices of female genital mutilation (FGM), early marriage (including abduction and forced marriage), and transactional sex - for example:

The socio-cultural attitude and practice of the society is one of the main root causes. Early marriage, the inequality between woman and man, FGM and marriage as a source of household income are some of the examples. For instance, early marriage is practiced widely in Ethiopia rural communities, by large for the sake of pride. Girls are cultivated, shaped and expected by the society to be good wives. In most rural parts of Ethiopia, girls get married early to control their sexual behaviour. Parents feel honoured when their daughter get married while a virgin. Otherwise she is considered a shame on the family. As a result of this norm it is not uncommon to see the reluctance of rural communities to send girls to school, particularly when the school is considered far. (NGO worker) (Ethiopia)

This NGO worker reflected on the specificities of rural settings as contexts where practices of early marriage and FGM, bound up with explicitly gendered norms, play a key role in SRGBV. This making bold of specific dimensions has the potential to support a well- 
contextualised approach to addressing SRGBV in policy and practice at national level, that has been heavily emphasised in international agendas.

Where Lombardo et al's notion of bending refers to a terminological misuse - we suggest making bold can be applied to reflect a more positive discursive move in two ways. Firstly, it can function to contribute to contextualising conceptualisations of SRGBV. Secondly, it can work to foreground less visible areas - in this case connected to the risks faced by young people staying away from home to attend secondary school in insecure accommodation, and questions of sexual subjectivity and agency. In both countries discussion of SRGBV became a site where socio-cultural traditions and practices came into dialogue with discursive framings of global policy organisations around gender, sexuality and agency - arguably with the potential for new and fruitful understandings to emerge between the different actors involved.

\section{Conclusion}

Examining the understandings of school-related gender-based violence (SRGBV) held by policy stakeholders in Ethiopia and Zambia, we have highlighted the ways in which this node of policy and practice is discursively shaped by different actors, in different contexts.

Drawing on Lombardo et al's conceptualisation of the 'discursive politics of gender equality' (2009), our analysis shows how national actors' understandings can narrow (through shrinking or fixing), shape (through stretching or bending) and emphasise (through making bold) different elements of the 'fixed' international consensus on the concept. We have shown how SRGBV can be stretched and certain elements made bold in ways that contribute to revealing and contextualising hidden and contested dimensions of SRGBV and its roots in inequalities in particular settings. Yet the concept is also discursively stretched, shrunk and 
fixed in ways that reflect understandings of gender that can support inequality or discrimination. Contestation over dimensions of SRGBV was live and ongoing between the policy actors, and was connected to their varying organisational positions, socio-cultural values, and exposure to particular narratives around violence. What is recognised as SRGBV, how it is understood, and how it should be addressed (though policy, programming, funds or other support) are up for grabs in these negotiations over meaning.

Our findings have implications at different levels. Firstly, they help to explain some of the challenges in reducing SRGBV, with varying understandings among policy actors about its nature and causes mapping on to varying perspectives about how to intervene. Secondly, we are reminded of the non-neutrality and ongoing mutability of the concept of SRGBV, and the importance of engaging with localised understandings and practices when making and enacting policy. Finally, there is the potential value in creating spaces where actors from different sectors, governmental and non-governmental organisations, and local feminist and women's rights organisations have the opportunity to reflect on and negotiate understandings and values associated with SRGBV. Building platforms and interactions that include a broad range of actors may contribute to furthering the complex dialogues which come into play in relation to SRGBV, due to its multi-dimensional nature, and could be a useful strategy.

\author{
Acknowledgments \\ [Removed for blind review]
}

\title{
References
}




\begin{abstract}
Abramowitz, S. \& Moran, M. (2012). International Human Rights, Gender- Based Violence, and Local Discourses of Abuse in Postconflict Liberia: A Problem of "Culture"? African Studies Review, 55(2), 119-146.

Ball, S. J. (1990). Politics and policy making in education. Oxon: Routledge.

Ball, S. J., Maguire, M. \& Braun, A. (2011). How Schools Do Policy: Policy Enactments in Secondary Schools. Oxon: Routledge.
\end{abstract}

Ball, S. J., Maguire, M., Braun, A. \& Hoskins, K. (2011a). Policy subjects and policy actors in schools: some necessary but insufficient analyses. Discourse: Studies in the Cultural Politics of Education, 32(4), 611-624.

Ball, S. J., Maguire, M., Braun, A. \& Hoskins, K. (2011b). Policy actors: doing policy work in schools. Discourse: Studies in the Cultural Politics of Education, 32(4), 625-639.

Centre for Applied Legal Studies (2014). Sexual Violence by Educators in South African Schools: Gaps in Accountability. South Africa: WITS University. Downloaded 17.10.19 https://www.wits.ac.za/media/wits-university/faculties-and-schools/commerce-lawand-management/researchentities/cals/documents/programmes/gender/Sexual $\% 20$ Violence $\% 20 \mathrm{by} \% 20$ Educators $\% 20 \mathrm{Si}$ ze $\% 20180270 \% 20 N E W . p d f$

Chikwiri, E. and Lemmer, E. M. (2014). Gender-based violence in primary schools in the Harare and Marondera districts of Zimbabwe. Journal of Sociology and Social Anthropology, 5 (1), 95-107.

DeJaeghere, J. \& Wiger, N. (2013). Gender discourses in an NGO education project: Openings for transformation toward gender equality in Bangladesh. International Journal of Educational Development, 33(6), 557-565. 
DHS (2011). Ethiopia Demographic and Health Survey 2011. Addis Ababa, Ethiopia and Calverton, Maryland, USA: Central Statistical Agency and ICF International.

DHS (2014). Zambia Demographic and Health Survey 2013-14. Rockville, Maryland, USA: Central Statistical Office, Ministry of Health, and ICF International: Retrieved from: https://dhsprogram.com/pubs/pdf/FR304/FR304.pdf

Ellsberg, M., Arango, D. J., Morton, M., Gennari, F., Kiplesund, S., Contreras, M, \& Watts, C. (2015). Prevention of violence against women and girls: what does the evidence say? Lancet, 385, 1555-66.

Heslop, J., Parkes, J., Johnson Ross, F., Alito, F., \& Turner, E. (2019). The Code of Conduct on Prevention of School-Related Gender-Based Violence: A study of policy enactment in Ethiopia. London: UCL Institute of Education.

Heslop, J., Parkes, J., Januario, F. \& Sabaa, S. (2017). Making meaning from data on schoolrelated gender-based violence by examining discourse and practice: insights from a mixed methodology study in Ghana and Mozambique. Compare: A Journal of Comparative and International Education, 49(1), 64-80.

Kaljee, L., Zhang, L., Langhaug, L., Munjile, K., Tembo, S., Menon, A., Stanton, B., Li, X., Malungo, J. (2017). A randomized-control trial for the teachers' diploma programme on psychosocial care, support and protection in Zambian government primary schools. Psychology, Health \& Medicine, 22(4), 381-392.

Kelly, L. (2005). Inside Outsiders. International Feminist Journal of Politics, 7(4), 471-495. Kyegombe, N., Namakula, S., Mulindwa, J., Lwanyaaga, J., Naker, D., Namy, S., Nakuti, J., Parkes, J., Knight, L., Walakira, E. and Devries, K. M. (2017). How did the Good School Toolkit reduce the risk of past week physical violence from teachers to students? Qualitative 
findings on pathways of change in schools in Luwero, Uganda. Social Science \& Medicine, $\underline{180,10-19 .}$

Leach, F., Dunne, M, \& Salvi, F. (2014). School-Related Gender-Based Violence: A global review of current issues and approaches in policy, programming and implementation responses to School-Related Gender-Based Violence (SRGBV) for the Education Sector. Paris: UNESCO Education Sector.

Le Mat, M. L. J. (2017). (S)exclusion in the sexuality education classroom: young people on gender and power relations. Sex Education, 17(4), 413-424.

Le Mat, M. L. J., Kosar-Altinyelken, H., Bos, H. M. W. \& Volman, M. L. L. (2019). Discussing culture and gender-based violence in comprehensive sexuality education in Ethiopia. International Journal of Educational Development, 65, 207-215.

Lombardo, E., Meier, P., \& Verloo, M. (Eds.). (2009). The Discursive Politics of Gender Equality: Stretching, Bending and Policymaking. New York: Routledge.

Maguire, M., Braun, A. \& Ball, S. (2015). 'Where you stand depends on where you sit': the social construction of policy enactment in the (English) secondary school. Discourse: Studies in the Cultural Politics of Education, 36(4), 485-499.

Matzopoulos, R. \& Myers, J. E. (2014). The Western Cape Government's new Integrated Provincial Violence Prevention Policy Framework: Successes and challenges. Aggression and Violent Behavior, 19(6), 649-654.

Mayeza, E. and Bhana, D. (2017). Addressing gender violence among children in the early years of schooling: insights from teachers in a South African primary school. International Studies in Sociology of Education, 26(4), 408-425. 
McNiff, J. \& Whitehead, J. (2011). All You Need to Know About Action Research, $2^{\text {nd }}$ edn, London: SAGE Publications.

Muhangi, G. (2017). Violence in Ugandan secondary schools. American Scientific Research Journal for Engineering, Technology, and Sciences (ASRJETS), 27(1), 291-308.

Mulugeta, E. (2016). Mapping Report for Young Lives Research Policy Program on Violence Affecting Children and Youth (VACAY).

Pankhurst, A., Negussie, N. \& Mulugeta, E. (2016). Understanding Children's Experiences of Violence in Ethiopia: Evidence from Young Lives. Innocenti Working Paper 2016-25. Florence: UNICEF Office of Research.

Parkes, J. (Ed.). (2015). Gender Violence in Poverty Contexts: The Educational Challenge. Abingdon: Routledge.

Parkes, J. (2016). The evolution of policy enactment on gender-based violence in schools. Prospects, 46, 93-107.

Parkes, J., Heslop, J., Johnson Ross, F., Westerveld, R. \& Unterhalter, E. (2016). A rigorous review of global research evidence on policy and practice on school-related gender-based violence. New York: UNICEF.

Parkes, J., Heslop, J., Oando, S., Sabaa, S., Januario, F. \& Figue, A. (2013). Conceptualizing gender and violence in research: insights from studies in schools and communities in Kenya, Ghana and Mozambique. International Journal of Educational Development, 33(6), 546-556.

Perryman, J., Ball, S., Braun, A., \& Maguire, M. (2017). Translating policy: governmentality and the reflective teacher. Journal of Education Policy, 32(6), 745-756. 


\begin{abstract}
J Peters, J. \& Wolper A. (Eds.) (1995). Women's Rights, Human Rights. New York: Routledge.
\end{abstract}

Ravi, S. \& Ahluwalia, R. (2017). What explains childhood violence? Micro correlates from VACS surveys. Psychology, Health \& Medicine, 22(1), 17-30.

SAQMEC (2007) The SACMEQ III project in Zambia. A study of the conditions of schooling and the quality of education. Retrieved from:

http://www.sacmeq.org/sites/default/files/sacmeq/reports/sacmeq-iii/nationalreports/s3_zambia_final.pdf

Sharma, P., Verma, G. \& Arur, A. (2013). Negotiating meanings of gender justice: Critical reflections on dialogs and debates in a non-governmental organization (NGO). International Journal of Educational Development, 33, 576-584.

Stromquist, N. (1997). Gender sensitive educational strategies and their implementation. International Journal of Educational Development, 17(2), 205-214.

Swainson, N. (2000). Knowledge and power: the design and implementation of gender policies in education in Malawi, Tanzania, and Zimbabwe. International Journal of Educational Development, 20(2000), 49-64.

UNESCO (2016). Global guidance on addressing school-related gender-based violence. Paris: UNESCO.

UNGEI (2018). A whole school approach to prevent school-related gender-based violence: Minimum Standards and Monitoring Framework. New York: UNGEI. 
Unterhalter, E. \& North, A. (2017, September). Gender, policy and contested practices. Paper presented at UKFIET the 14th International Conference on Education and Development. Oxford: UK.

USAID (2016). Conceptual Framework for Measuring School-Related Gender-Based Violence. Washington, DC: USAID.

Viczko, M. \& Riveros, A. (2015). Assemblage, enactment and agency: education policy perspectives. Discourse: Studies in the Cultural Politics of Education, 36(4), 479-484. 